\title{
Deposit Formation from Urea Injection: a Comprehensive Modeling Approach
}

\author{
U. Budziankou ${ }^{1}$ (D) $\cdot$ M. Börnhorst ${ }^{2} \cdot$ C. Kuntz $^{2} \cdot$ O. Deutschmann ${ }^{2} \cdot$ T. Lauer $^{1}$
}

Received: 10 September 2019 /Revised: 28 December 2019 / Accepted: 1 February 2020 / Published online: 12 February 2020

(C) The Author(s) 2020

\begin{abstract}
Long-term reliability is one of the major requirements for automotive exhaust aftertreatment systems with selective catalytic reduction (SCR) using urea water solution (UWS) as $\mathrm{NH}_{3}$ carrier fluid. A high injection rate of UWS or unfavorable operating conditions may lead to formation of solid deposits, which decrease system efficiency by increasing backpressure and impairing ammonia uniformity. A reliable numerical prediction of deposit formation in urea SCR systems is desired for optimization of system design. However, comprehensive modeling of physical and chemical processes in the tailpipe as well as different time scale phenomena represents a challenging task. This study presents a comprehensive approach for modeling UWS injection, droplet impingement, liquid film and deposit formation based on CFD-simulation. An existing kinetic model for urea decomposition is integrated into the CFD code to predict solid by-product formation from wall films. Physical simulation time is extensively increased by substituting the Lagrange-particles with source terms of mass, momentum and energy reducing simulation time by a factor of 20 . The comparison of measured and simulated results shows the capability of the presented modeling approach to predict position and chemical composition of solid deposits.
\end{abstract}

Keywords Selective catalytic reduction $\cdot$ Computational fluid dynamics $\cdot$ Detailed chemistry $\cdot$ Transient long-time simulation

\section{Introduction}

Selective catalytic reduction (SCR) is a widely applied exhaust gas aftertreatment measure to reduce nitrogen oxide (NOx) emissions of both light and heavy-duty vehicles. Due to safety reasons, the reducing agent ammonia is supplied to the exhaust duct by an aqueous urea solution (32.5 wt.- $\%$ urea) commonly called AdBlue ${ }^{\circledR}$ or diesel exhaust fluid (DEF). Due to highly transient operating conditions (OC) and space restrictions, injection of the liquid may result in

Electronic supplementary material The online version of this article (https://doi.org/10.1007/s40825-020-00159-x ) contains supplementary material, which is available to authorized users.

U. Budziankou

uladzimir.budziankou@ifa.tuwien.ac.at

M. Börnhorst

marion.boernhorst@kit.edu

1 Institute for Powertrains and Automotive Technology, Vienna University of Technology, Vienna, Austria

2 Institute for Chemical Technology and Polymer Chemistry, Karlsruhe Institute of Technology, Karlsruhe, Germany incomplete evaporation and spray impingement on the wall. As a result, liquid films are formed on mixer blades or tailpipe walls [1-6]. Subsequent evaporation and urea reactions induce the formation of solid deposits $[4,5,7,8]$. Apart from ammonia, which is the desired product for SCR, solid byproducts like biuret, cyanuric acid or ammelide can be formed from the liquid film [9-11]. Solid deposits negatively affect system efficiency, as they increase back pressure and decrease ammonia uniformity. Therefore, a fundamental understanding of deposit formation is essential for a reliable prediction by numerical tools, which are used for system design and optimization.

Numerous authors studied the formation of solid deposits due to injection of urea water solution (UWS) experimentally $[4,5,7,12,13]$. Numerical investigations (CFD) in literature focus on relevant physical processes, such as spray injection and propagation $[1,14,15]$, the performance of mixing elements $[4,16-18]$ and droplet evaporation [19-22] as well as impingement and film formation [1, 2, 23]. Kinetic models for urea decomposition are available containing thermolysis, hydrolysis and further reactions forming biuret, triuret, cyanuric acid and ammelide [11, 24]. However, integration of the chemical reactions of urea decomposition to CFD models is 
mostly limited to urea thermolysis and hydrolysis reactions in the gas phase directly relevant for ammonia production $[1,4$, $15,19,25,26]$. Liquid films resulting from spray/wall interaction consist of the two components - urea and water [4, 19]. Urea reactions are not accounted for in the liquid film. A risk for solid deposits was derived from concentration and temperature data of the liquid film by Smith et al. [4].

Schellander et al. [27] extended a CFD model of relevant physical phenomena in the mixing section of SCR systems in FIRE by a detailed decomposition model proposed by Brack et al. [11]. The implementation of the chemical kinetics was tested by comparison of the experimentally determined and simulated mass loss of a biuret sample during heat-up in a flow setup. The model was further applied for simulations of a test rig. By this approach, decomposition of urea to various solid by-products was modeled in the liquid film. Results show good agreement with experimental data in terms of form and location of the liquid film. However, the liquid film composition was not validated by experimental results. For simulation of 16-s test rig operation ( 390.000 cells) 16 CPUs were used for $13 \mathrm{~h}$ wall-clock time.

Habchi et al. [28] included a semi-detailed kinetic model for urea decomposition in a CFD model of a SCR mixing section. Urea decomposition and the formation of solid byproducts were described by 12 reactions. Physical properties of the different compounds were approximated by data for water. As no heat transfer model was implemented for liquid-solid contact, the wall temperature was assumed to be equal to the gas temperature. Simulation results reveal two temperature regimes for deposit formation. However, no validation by experimental results was performed concerning urea decomposition or the composition of the liquid film. Due to high computational costs resulting from the coupling of kinetic models with a CFD model in the context of UWS injection and decomposition, the simulation time was limited to $1 \mathrm{~s}$ while using 256 cores for 1 week of wall clock time. The test rig geometry consisted of about one million cells.

High computational costs result from the different time scale phenomena relevant for deposit formation. While spray injection and propagation take place in time scales less than milliseconds, film and deposit formation occur in time scales of minutes. With regard to the simulation wall time, modeling of the spray propagation and the droplet impingent is most critical. Most commercial CFD codes use a Lagrangian based particle tracking method for computation of spray behavior in a SCR mixing section. The spray is presented by stochastic particles, so-called parcels [29], which contain droplets with equal properties. A good statistical representation of the spray is reached by a high number of injected parcels of more than 10,000 per seconds. $[30,31]$. Conservation equations for mass, momentum and energy are solved for each parcel.

The modeling of the Lagrangian phase in the simulation domain increases the simulation time up to $30 \%$ [27]. The modeling effort is nearly direct proportional to the injection time due to the rise of parcels in a fluid domain. Further, the presence of Lagrangian particles limits the numerical simulation time step to the range of approx. $0.1-1 \mathrm{~ms}[27,32,33]$. Moreover, the UWS injection is a periodic process and, thus, must be simulated many times until the wall film has sufficiently propagated and deposit formation or decomposition is observed.

A look into literature shows different speed-up methods applied for the modeling of deposit formation. Schellander et al. [27] developed a method to reduce computational costs based on pre-simulation of Lagrangian phase data and frozen flow fields. After pre-simulation of one injection period, information of the wall nearest droplets was stored for the use in transient simulations. Droplet information was taken from the pre-simulation database for each time step, resulting in a $30 \%$ reduction of computational time.

Birkhold et al. [1] and Smith et al. [32] applied a similarity principle to lower the timescale of solid cooling. In order to attain the equilibrium temperatures of solid components faster, their density $(\mathrm{kg} / \mathrm{m} 3)$ and hence their thermal mass were reduced. The simulation time required to capture the cooling processes and the evolution of the film pathways was reduced significantly. Smith presented simulation results for $40-\mathrm{s}$ test bench operation. No information about the required runtime was given.

This study presents a comprehensive modeling approach for physical and chemical processes involved in the formation of solid deposits from urea. This includes injection, spray/wall interaction, evaporation, liquid film formation and urea reactions forming solid by-products. In order to speed up the simulation runtime and hence accomplish the modeling of deposit formation within typical time ranges of several minutes, an injection source approach was developed. In this approach, the numerical parcels representing the spray are substituted by source terms of mass, momentum and energy that are directly applied to the film and gas phase. Model validation is performed by experimental results from an engine test bench and subsequent deposit analysis demonstrating the capability of the modeling approach to predict deposit formation in real scale systems.

\section{Experimental Setups and Methods}

This section presents the setup for investigations on film and deposit formation and methods for chemical analysis of generated deposits.

\subsection{Engine Test Bench Setup}

For validation of both the applied simulation models and the new speed-up method, experimental results from an engine 
test bench, as shown in Fig. 1 a, were used. Its design allows the study of following physical and chemical processes under engine typical OC:

- spray/wall impingement under a wide range of surface temperatures and realistic spray properties

- liquid film formation and propagation on a straight surface

- formation of solid deposit from a liquid film

- wall cooling due to the spray impingement or the evaporation of a liquid film

In order to avoid the modeling of complex turbulent flow and hence facilitate the validation of simulation models, a uniform and unidirectional flow with fine-scale and isotropic turbulence was generated in the measurement volume of the optical box. For this reason, an inlet section with a cone angle of $7^{\circ}$ followed by an uncoated monolith (CAT1) was implemented (see Fig. 1b). Downstream of the measuring section a second uncoated monolith (CAT2) separated any liquid urea from the exhaust gas.
The measurement volume of the box $(200 \times 200 \times$ $600 \mathrm{~mm}$ ) was designed to enable optical access to the deposit formation process mentioned above. A horizontal impingement plate made of widely used steel $\mathrm{X} 5 \mathrm{CrNi} 18-10$ with a thickness of $2 \mathrm{~mm}$ and the surface roughness $\mathrm{Ra}<0.5 \mu \mathrm{m}$ was placed in the middle of the box. The straight plate allows unhindered propagation of the liquid film with long pathway. The liquid film was produced by an AdBlue injector installed on the topside of the box. AdBlue was supplied by a flexible and mobile supply and control unit. For observation of the liquid film and the formation of solid deposits, the box was equipped with three large borosilicate glasses.

The cooling of the bottom side of the impingement plate was measured with an IR-camera through zinc selenide windows ( $\mathrm{Zn}-\mathrm{Se})$, which have a high transmissivity in the IR spectrum range. In order to increase the surface emissivity, the bottom side of the plate was varnished with black lacquer. Additionally, a line pattern was carefully scratched in the lacquer for spatial information. For calibration of the IR-camera, two thermocouples were soldered on the plate within the observation area of the camera.
Fig. 1 a Schematic of engine test bench setup for investigation of deposit formation; b CAD, model of the optical box

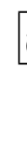
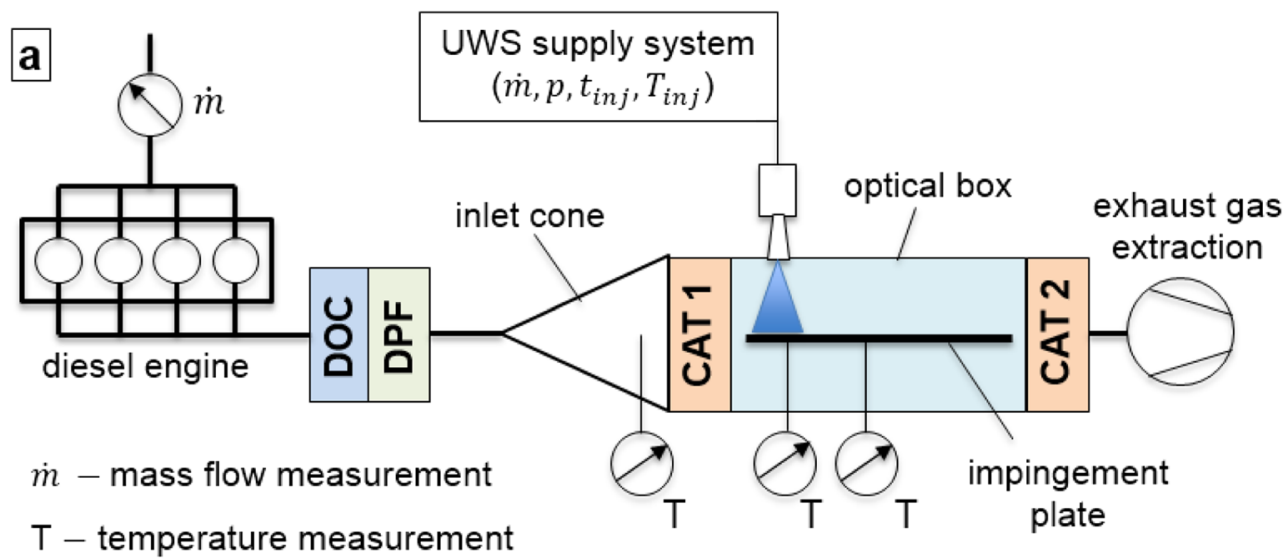

$\mathrm{T}$ - temperature measurement

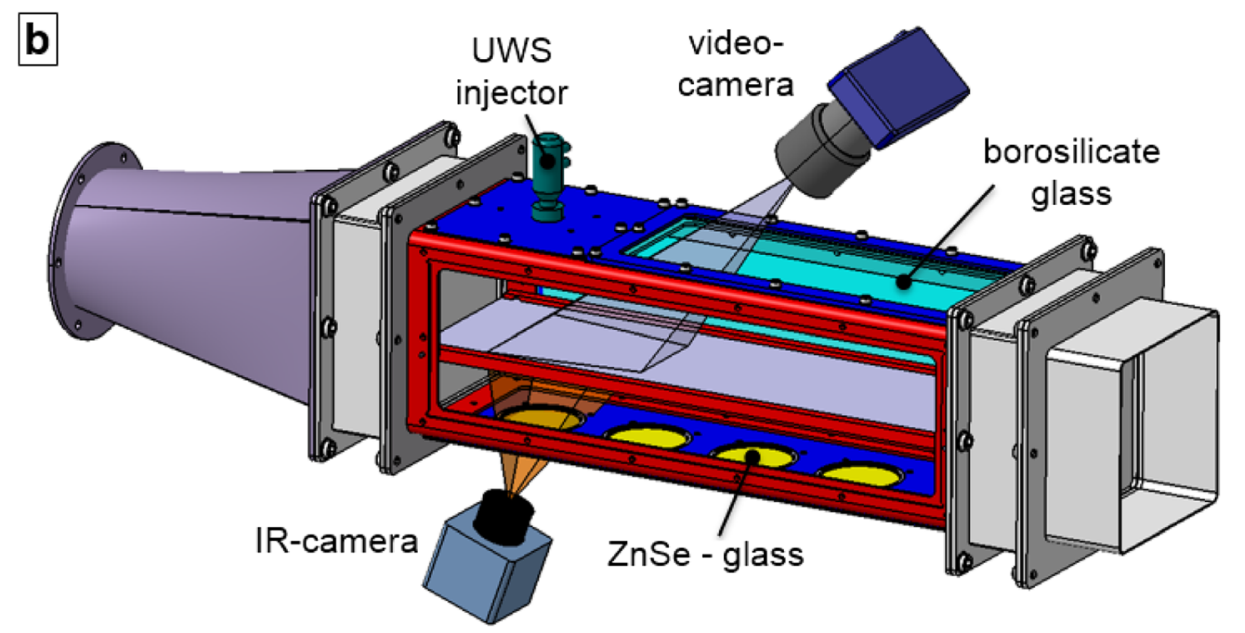


For validation of the simulation models, two experiments were chosen as shown in Table 1. The choice was based on the following criteria:

- generation of solid deposits during the first $3 \mathrm{~min}$ of the experiment, which is important due to the limited simulation time

- the mass of obtained solid deposits had to be sufficient for the subsequent chemical analysis with TGA or HPLC methods

- possibility to validate the applied physical model for different wall wetting regimes (experiment 1)

- possibility to validate the chemical solver with regard to the decomposition of solid deposits (experiment 2)

The OCs of the experiment 1 are typical for a higher load point of a diesel engine. Due to the heat radiation, at the beginning of the experiment the steady state temperature of the impingement plate was approx. $40{ }^{\circ} \mathrm{C}$ less than the temperature of the exhaust gas. Nevertheless, it was sufficiently high to cause the Leidenfrost effect during the first $15 \mathrm{~s}$ of the experiment. After this time, the critical wall temperature was reached, which triggered wall wetting and the subsequent formation of solid deposits. AdBlue was being injected during the whole experiment. The video recording of the experiment shows a permanent accumulation of solid deposits.

The OCs of the experiment 2 represents a medium load point of a diesel engine. The initial steady state temperature of the impingement plate was approx. $245^{\circ} \mathrm{C}$, which is $30^{\circ} \mathrm{C}$ less than the temperature of the exhaust gas. The liquid film was being produced during the first $5 \mathrm{~min}$ of the experiment by the injection of AdBlue. Then the injection was stopped. A fast evaporation of the liquid film and a slow decomposition of solid deposits were visually observed during the next $15 \mathrm{~min}$ of the experiment.

Two different commercial injectors were applied for the film generation in the experiments 1 and 2 . They cover a wide range of droplet Weber-numbers and specific area load, which are known to have a crucial impact on the spray impingement regimes and the wall cooling [6,34-36]. The spray characteristics of both injectors are shown in Table 2 .

After each experiment, solid deposits were removed from the impingement plate and stored in a hermetic container for chemical analysis. The applied analytical methods are explained in the following chapter.
Table 2 Spray characteristics

\begin{tabular}{lll}
\hline Injectors & 1 & 2 \\
\hline Number of holes & 3 & \\
Injection velocity $(\mathrm{m} / \mathrm{s})$ & 23 & \\
Injection frequency $(\mathrm{Hz})$ & 1 & \\
Injection pressure (absolute) (bar) & 6 & \\
Static mass flow $(\mathrm{kg} / \mathrm{h})$ & 3.18 & 7.32 \\
$\mathrm{SMD}(\mu \mathrm{m})$ & 84 & 178 \\
Dv90 $(\mu \mathrm{m})$ & 230 & 380 \\
Angle of a spray cone $\left({ }^{\circ}\right)$ & 6 & 11 \\
We-number (calculated with $\mathrm{SMD})(-)$ & 673 & 1427 \\
Area load at the distance of $0.05 \mathrm{~m}\left(\mathrm{~g} / \mathrm{m}^{2} \mathrm{~h}\right)$ & $48 \mathrm{E}^{6}$ & $99 \mathrm{E}^{6}$ \\
\hline
\end{tabular}

\subsection{Analytics}

Deposits generated and sampled from the test rig are subsequently analyzed in terms of chemical composition by thermogravimetric analysis (TGA) and high-performance liquid chromatography (HPLC).

Thermogravimetric analysis is performed in a Netzsch STA $409 \mathrm{C}$ instrument. Deposit samples from the test rig are grinded and an initial sample mass of $10 \mathrm{mg}$ is arranged in a cylindric corundum crucible. Using a constant heating rate of $2 \mathrm{~K} / \mathrm{min}$, the sample is heated from 40 to $700^{\circ} \mathrm{C}$. Synthetic air $(20.5 \% \mathrm{O} 2$ in N2) is used as purge gas with a flow of $100 \mathrm{ml} /$ min. Measurements reveal the sample mass loss due to evaporation and chemical reactions over temperature. Normalization by the initial sample mass is performed for the presentation of the measurement results. In addition to measurements on the deposit samples, reference measurements are performed with pure cyanuric acid (Sigma Aldrich, purity $\geq 98 \%$ ).

For quantitative analysis of the deposits' composition, HPLC measurements are performed. The method applied for the measurements was specifically designed for chemical characterization of urea deposits and was adapted from previously published methods [37, 38]. It includes urea, biuret, triuret, cyanuric acid, ammelide, ammeline and melamine. A Hitachi VW12 HPLC instrument with a L-2200 sampler is employed for the measurements. Signal analysis is performed downstream the column (Waters IC-PAK Anion HC) by a L2455 diode array detector. A N2HPO4 buffer solution is used as mobile phase after filtration with a constant flow of $0.5 \mathrm{ml} /$

Table 1 Experimental conditions

\begin{tabular}{lllllll}
\hline Experiment $\mathrm{N}^{\circ}$ & $\begin{array}{c}\dot{m}_{\text {ex.gas }} \\
(\mathrm{kg} / \mathrm{h})\end{array}$ & $T_{\text {ex. gas }}\left({ }^{\circ} \mathrm{C}\right)$ & Injector $\mathrm{N}^{\circ}$ & Duration of experiment (min) & Duration of AdBlue injection (min) & Injection rate (mg/s) \\
\hline 1 & 1200 & 350 & 2 & 20 & 20 & 61 \\
2 & 1000 & 275 & 1 & 20 & 5 & 35 \\
\hline
\end{tabular}


min at $25^{\circ} \mathrm{C}$. As results reveal a strong sensitivity on $\mathrm{pH}$, the solution was kept at $\mathrm{pH}=10.4$ constantly. Calibration was performed in advance by standard solutions.

Deposit samples are grinded and dissolved in the eluent. Initially, a sample of $15-20 \mathrm{mg}$ is dissolved in $100 \mathrm{ml}$ of the eluent. Further dilution was required in case of poor solubility of the sample or to meet the respective calibration range of a species. With this method, the composition of the deposit samples can be determined with an accuracy of $<5 \%$ for urea, $<10 \%$ for biuret, $<30 \%$ for triuret, $<10 \%$ for cyanuric acid, $<20 \%$ for ammelide, $<10 \%$ for ammeline and $<20 \%$ for melamine.

\section{Modeling}

In the following chapter, the numerical modeling of liquid film and deposit formation is presented in detail.

\subsection{Physical Models and Numerical Setup}

The numerical modeling of both described experiments was carried out within the CFD code Star-CCM+ v13.06. It consisted of a set of consecutive simulations:

1. Steady-state simulation of stationary flow and temperature field including all parts of the test bench. The calculated data were then used as initial and inlet conditions for subsequent unsteady simulations.

2. Unsteady simulation of one injection cycle including Lagrangian approach for the modeling of the AdBlue injection. In order to reduce simulation effort, fluid regions upstream of the measurement volume were deleted from the simulation domain. The required inlet conditions were imported from the steady-state simulation mentioned above. The simulation was carried out with a time step of $0.3 \mathrm{~ms}$ and 7 inner iterations, which was enough for the accurate modeling of the Lagrangian phase. During this simulation, source terms of mass, momentum and energy were determined simultaneously for both gas and liquid film phases.

3. Unsteady simulation of liquid film and deposit formation with the pre-calculated source terms. The time step was increased to $10 \mathrm{~ms}$ while maintaining the same number of inner iterations. As will be shown below, this numerical setup was sufficient for the accurate modeling of the film motion and evaporation as well as the modeling of chemical reactions. For further reduction of the simulation effort, the flow field of the exhaust gas was frozen as proposed by Schellander [27]. A simulated physical time of approx. $45 \mathrm{~s}$ /day was achieved by using of a computer core (Intel Xeon CPU E5-2660 v2 (2.20 GHz)) per 35,000 cells.
For the modeling of the gas flow in all simulations, a RANS (Reynolds-averaged Navier-Stokes) approach was used with a Lag Elliptic Blending k- $\varepsilon$ realizable turbulence model. The heat exchange between solid parts of the box and the exhaust gas was simulated with the help of the conjugate heat transfer model [33]. A combination of the Gray Thermal Radiation and the Surface-to-Surface Radiation model [33] was used to reproduce the cooling of solid walls due to thermal radiation.

The volume mesh of the optical box and the monolith downstream (see Fig. 1a) are shown in Fig. 2. For the modeling of the liquid film, a shell region was created on the topside of the impingement plate. In order to represent the uncoated monolith downstream the box, a volume mesh was extruded from the outlet of the fluid region.

A grid dependency analysis was carried out to optimize the simulation effort and accuracy in the following numerical investigations. Simulations with a cell base size of $2 \mathrm{~mm}$ showed reasonable results for the velocity field inside the optical box. Furthermore, the impact of the wall treatment on the convective heat transfer between the gas flow and the impingement plate was studied. For this reason, the temperature field of the plate was modeled with both low and high $\mathrm{y}^{+}$ wall treatment approaches at steady-state OC of the experiment 1 . The obtained temperature field of the plate is the resulting equilibrium state between the convective heat transfer from the exhaust gas to the plate and the heat loss of the plate due to the heat radiation. As shown in Fig. 3, the simulation result obtained with resolved viscous sublayer (7 prism layers) and low $\mathrm{y}^{+}$wall treatment has a very good agreement with the measurement data. In contrast, the simulation with not resolved viscous sublayer ( 3 prism layers) and high $\mathrm{y}^{+}$ wall treatment overestimated the resulting temperature field by more than $10^{\circ} \mathrm{C}$.

The physical models applied for the simulation of UWS spray and liquid film are mainly based on the work by Fischer [30] and the SCR best practices guide by the software producer [33]. The spray deceleration by the exhaust gas was simulated by the modified Schiller-Naumann drag force model [39]. The modified Wruck impingement heat transfer model [40] was applied for the modeling of heat exchange between the spray and the impingement plate if its surface temperature was above the critical value. The droplet impingement was simulated according to the modified Bai-Onera impingement model [41]. The two-dimensional, finite volume model [33] was applied for the modeling of liquid film. The kinetic model for urea decomposition and by-product formation is integrated by user-coding based on the algorithm of a multi-phase batch reactor model in DETCHEM ${ }^{\mathrm{TM}}$ [42].

The modified Schiller-Naumann, Wruck and Bai-Onera models can be found in the final report of the research project "AdBlue Deposits" supported by the Research Association for Combustion Engines. The focus of current work is the applied 
Fig. 2 Numerical mesh of the measuring section

Fig. 3 Temperature field of the impingement plate prior to the AdBlue injection for the experiment 1. (a) Measurement result; (b) simulation result with resolved viscous sublayer and low $\mathrm{y}^{+}$wall treatment; (c) simulation result with not resolved viscous sublayer and high $\mathrm{y}^{+}$wall treatment
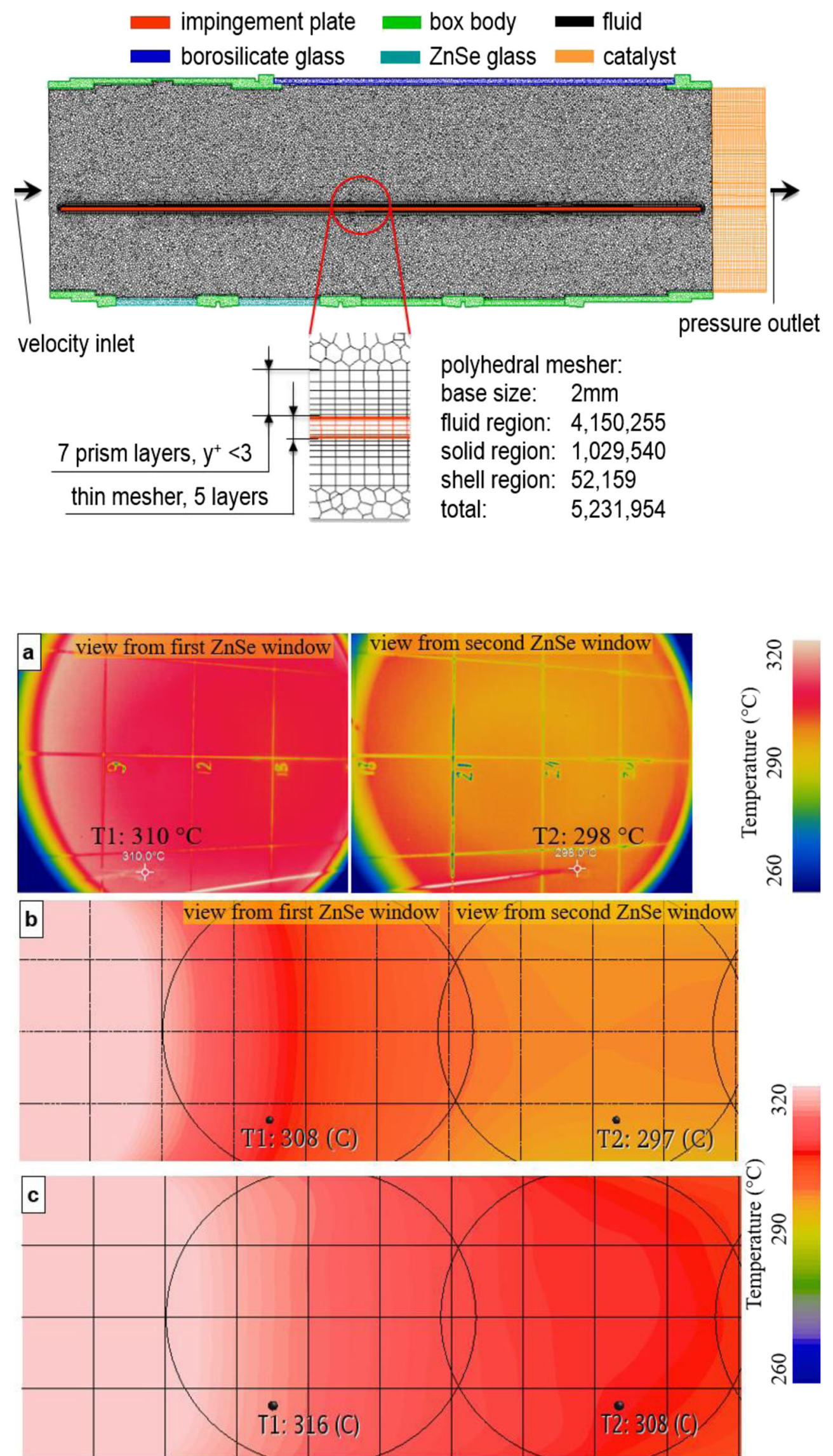

$\stackrel{\circ}{\circ}$ 
speed-up method and the coupling of the detailed chemical solver DETCHEM ${ }^{\mathrm{TM}}$ with the used CFD code.

\subsection{Injection Source Approach}

In order to speed up the simulation time and hence accomplish the modeling of deposit formation with typical time ranges, a new speed-up method called "injection source approach" was developed. In this approach, the numerical parcels representing the spray are substituted by source terms of mass, momentum and energy that are directly applied to the film and gas phase. The source terms for both phases were calculated simultaneously during a single injection event. The obtained sources can be used as long as the OC remain constant, i.e. as long as the spray deflection and the impingement positions of droplets are not changing. When simulating transient OCs, the source terms must be updated continuously with the specific combination of spray and exhaust mass flow. In the following, the calculation of source terms for the gas and film phase will be described in detail.

\subsection{Calculation of the Source Terms for the Gas Phase}

The source terms applied to the gas phase should represent the spray behavior in the exhaust gas flow, i.e. mass and energy transfer between the spray and the gas phase as well as the momentum exchange between both phases. Three required source terms can be calculated during an unsteady simulation of one injection cycle. During this simulation, following values should be determined in each fluid cell for each time step:

1. Mass of water and urea $\mathrm{m}_{g i}$ evaporated from droplets. For this purpose, the evaporation rate of a species " $i$," which was calculated by the multicomponent lumped evaporation model [33], was multiplied with the duration of the current time step.

2. Evaporation heat $Q_{g}$, which is the product of the enthalpy difference between the liquid and gaseous species and its evaporated mass.

3. Momentum $p_{g}$, which is the product of forces acting between a droplet and the gas flow and the duration of the current time step.

The values of $m_{g i}, Q_{g}$ and $p_{g}$ were cumulated during the whole simulation time and then normalized to the cell volume and the used injection time.

The obtained data $\sum \bar{m}_{g i}, \sum \bar{Q}_{g}$ and $\sum \overline{\vec{p}}_{g}$ are source terms for mass, energy and momentum, respectively. The normalized terms can be applied to each desired injection time.

\subsection{Calculation of the Source Terms of the Fluid Film Phase}

As mentioned above, the calculation of source terms for the film phase was conducted simultaneously with those for the gas phase. During the unsteady simulation of one injection cycle, properties of the impinging droplets were analyzed and the following values were determined:

1. Mass of an impinging droplet, which remains at the impingement position if the surface temperature is below the critical wall temperature $T_{s}<T_{\text {crit }}$ (hereafter called as "sticking mass" $m_{s}$ ).

According to the applied Bai-Onera impingement model, the sticking mass depends only on the surface temperature and the impact K-number [43].

$K=W e_{n} \cdot O h^{-0.4},[-]$

Where $W e_{n}$ and $O h$ denote the normal impact Weber number and the Ohnesorge number, respectively.

As long as the OCs are not changing, the impact of the gas flow on the droplets is not changing as well. Droplet trajectories and thus impact $\mathrm{K}$-numbers of droplets will remain the same for each injection. Therefore, only changing surface temperature, due to surface cooling by film evaporation, may lead to a change of the sticking mass. In order to obtain a mass source, which is valid for different surface temperatures $T_{s i}$, sticking mass $m_{s, T_{s i}}$ should be calculated for different surface temperatures $T_{s i}$ in advance, e.g. 280, 260, 240, 220, 200 and $160{ }^{\circ} \mathrm{C}$. These values cover the temperature range with the highest changing gradients of the sticking mass. Below the surface temperature of $160{ }^{\circ} \mathrm{C}$, the temperature impact on droplet impingement is considered as negligible [44].

Due to the fact that spray droplets evaporate in the hot exhaust gas and hence have different concentrations of water and urea, $m_{s, T_{s i}}$ should be determined for each species:

$m_{s i, T_{s i}}=m_{s, T_{s i}} \cdot c_{i},[g]$

Where the $c_{i}$ is the current species concentration in the impinging droplet.

2. Product of the incident droplet mass and droplet temperature $m_{d i} \cdot T_{d i}$, which is necessary for further calculation of the mass averaged temperature of source species.

3. Momentum from a droplet to the film $\vec{p}_{f}$, which is usually accessible in commercial CFD codes.

4. Impingement heat $Q$ transferred from a hot surface to a droplet if $T_{s} \geq T_{\text {crit }}$. According to the used Wruck impingement heat transfer model [40], $Q$ depends only on the 
surface temperature for steady-state OCs as shown in Eq. (3). Similar to the sticking mass, the impingement heat is calculated for different surface temperatures $T_{\boldsymbol{s}, i}$ in advance, e.g. $450,300,280,260$ and $240{ }^{\circ} \mathrm{C}$.

$Q_{T_{s i}}=-A_{\text {cont }} \cdot h \cdot\left(T_{s, i}-T_{d i}\right) \cdot c,[J]$

Where $h$ is the impingement heat transfer coefficient, $A_{\text {cont }}$ effective contact area, $T_{d i}$ temperature of an impinging droplet and $c$ the droplet count in a parcel.

The values $m_{s i, T_{s i}}, \mathrm{Q}_{T_{s i}}, \vec{p}_{f}$ and $m_{d i} \cdot T_{d i}$ were cumulated during the entire simulation time for each surface cell and then normalized to the cell area and the used injection time. In order to obtain mass and heat sources, which are valid for the current surface temperature, a linear interpolation between pre-calculated values of $\Sigma \bar{m}_{s i, T_{s i}}$ or $\Sigma \bar{Q}_{T_{s i}}$, respectively, was carried out. The cumulated value $\Sigma \overrightarrow{\vec{p}}_{f}$ was the source term of momentum applied to the film region during injection time.

In order to obtain the correct mass averaged temperature of the species produced by the mass sources, the cumulated product of $m_{d i} \cdot T_{d i}$ must be divided by the cumulated impinged mass:

$T_{\text {species }}=\frac{\sum\left(m_{d i} \cdot T_{d i}\right)}{\sum m_{d i}},\left[{ }^{\circ} C\right]$

\subsection{Implementation of Chemical Kinetics}

A kinetic model for urea decomposition adapted from Brack et al. [11] is implemented to the CFD model by user-coding. The numerical algorithm of the DETCHEM ${ }^{\text {TM }}$ Multiple Phase Tank Reactor (MPTR) package [45] is translated to userdefined functions. This procedure establishes an interface between the CFD code and the OD chemistry model in the fluid film. Concentration, temperature and pressure data are transferred from the CFD code to the user code for each liquid film cell in each time step. From these data, reaction rates are calculated by the user-coded algorithm. The complex chemistry model can call resulting production terms in the fluid film in order to update the species concentrations in each time step. No interface exists between the user code and the Lagrangian phase, as urea decomposition was found to be negligible in the simulations due to small droplet lifetime. All physical processes, e.g. gas-liquid equilibria, are calculated in the CFD code independently from the user code.

The numerical model implemented to the user code represents a $0 \mathrm{D}$ batch reactor model containing one gaseous and multiple condensed, ideally mixed phases. Besides the gaseous (g) phase, one liquid (l), one aqueous (aq) and multiple solid (s) phases are considered. The phase volumes are assumed to be layered on top of each other and connected by an interface of defined size. Here, the interface area is equal to the cell area. Phase transitions are implemented by two different species, as the species are assigned to respective phases. Reaction rates $r_{k}$ are expressed by an extended Arrhenius term

$$
r_{k}=A_{k} T^{\beta_{k}} \exp \left(-\frac{E_{A, k}}{R T}\right) \prod_{S_{i} \in R_{k}} c_{i}^{\tilde{\mathrm{v}}_{i k}}
$$

where $A_{k}$ represents the pre-exponential factor, $\beta_{k}$ the temperature exponent, $E_{A, k}$ the activation energy, $R$ the gas constant and $\tilde{v}_{i k}$ the concentration exponent. For evaporation and condensation, reaction rates are calculated by Eq. (6) representing Herz-Knudsen equation and Eq. (7) based on kinetic gas theory. $\alpha_{c}$ denotes an accumulation factor, $M_{i}$ the specific molar mass and $h$ the Henry constant given by Eq. (8).

$$
\begin{aligned}
& r_{k}^{\text {evaporation }}=\alpha_{c} \sqrt{\frac{R T}{2 \pi M_{i}}} \frac{c_{i}^{\text {liq }}}{h} \\
& r_{k}^{\text {condensation }}=\alpha_{c} \sqrt{\frac{R T}{2 \pi M_{i}}} c_{i}^{\text {gas }} \\
& h=\frac{\rho_{i}^{\text {liq }}}{p_{i}^{\text {vap }}} \frac{R T}{M_{i}}
\end{aligned}
$$

$c_{i}$ and $\rho_{i}$ represent the species concentration and density in the respective phases. $p_{i}^{v a p}$ denotes the vapor pressure. Production rates $\dot{n}_{i k}$ for the species $i$ for homogeneous and heterogeneous reactions are given by Eqs. (9) and (10) in dependence on the stoichiometric coefficient $\nu_{i k}$ as well as the phase volume $V_{j}$ and interface area $A$, respectively.

$\dot{n}_{i k}=V_{j} \nu_{i k} r_{k}$

$\dot{n}_{i k}=A \nu_{i k} r_{k}$

Species and enthalpy conservation Eqs. (11) and (12) are solved by the LIMEX solver [45].

$\frac{\mathrm{d} n_{i}}{\mathrm{~d} t}=\sum_{R_{k}} \dot{n}_{i k}$

$\frac{\mathrm{dH}}{\mathrm{d} t}=A k_{w}\left(T^{e x t e r n}-T\right)$

$k_{w}$ denotes the heat transfer coefficient, $T^{\text {extern }}$ the external temperature given by the heating rate. Total enthalpy $H$ is expressed by

$H=\sum_{S_{i}} n_{i} H_{i}(T)$

The kinetic parameters were adapted and enhanced based on the work of Brack et al. [11] by kinetic data derived from TGA. The applied kinetic scheme is given by Table 4 in the 
supplemental material. The model considers urea, biuret, triuret, cyanuric acid and ammelide. Since the MPTR model considers multiple condensed phases, pseudo-liquid species are defined in the fluid film model in StarCCM+, which represent solid or aqueous species. Thermophysical properties for all relevant species are summarized in a species database, which is implemented to StarCCM+. A detailed description of the implemented property data for all relevant species in the respective phases is given in the supplemental material.

In the user code, type definitions for variables and functions, mathematical functions and user accessible data are loaded. A user function is created, which results in an array containing production terms for all relevant species in the units of $\mathrm{mol} / \mathrm{kg} / \mathrm{s}$. The numerical and kinetic algorithm for calculating the production terms is implemented to the user function. Based on the specific mole fraction, which is transferred from the CFD code, mixture densities and molar concentrations of all species present in the liquid film are calculated. In the CFD code, the liquid film represents liquid, aqueous and solid phase. The total amount of each species and the volume of each phase are determined in order to calculate the species concentrations for each phase ( 1 , aq and $\mathrm{s})$.

After compilation to a user library, the user code is loaded to Star-CCM+. In the fluid film model, the user function is integrated to the complex chemistry model as species source.

\section{Results}

For validation of the simulation results, the experimental data shown in Table 1 were used. To speed up the simulation time, the injection source approach was applied. The source terms for the liquid film and the gas phase were calculated during a single injection event and further applied for the modeling of liquid and deposit formation. Figure 4 illustrates a mass and heat source, which was applied to the film phase on the impingement plate at OCs of the experiment 1 . Due to the fact that the initial temperature of the impingement plate was above the critical wall temperature, the liquid film formation was impeded at the beginning of the simulation. Therefore, only the heat source was applied to the film phase which reproduced the impingement heat transfer between the spray and surface of the plate, see Fig. 4 a left. In the right picture the absence of any liquid deposition due to the Leidenfrost effect is shown.

Due to the cooling of the impingement plate by the applied heat source, the plate temperature attained the critical wall temperature. Now, the mass sources of water and urea are activated and the cooling of the plate is calculated as heat conduction between the liquid film and the surface of the plate. Figure $4 \mathrm{~b}$ illustrates the heat and mass sources of urea after $60 \mathrm{~s}$. The heat source is zero where the local surface temperature is below the critical wall temperature, see Fig. 4 $\mathrm{b}$ left.

Figure 5 shows the simulated and experimentally observed liquid film and solid deposit accumulated after $180 \mathrm{~s}$ of the AdBlue injection. Figure 5 a illustrates the thickness of the liquid film including both liquid and pseudo-liquid species (solid deposits). Figure $5 \mathrm{~b}$ shows only solid deposits dissolved in the film. Overall, a good agreement with the experimental data can be observed. The solid deposits were produced in the whole wetted area of the plate and then transported downstream to the edge of the liquid film. The simulated spreading area of the liquid film was slightly overestimated. The main reason for this is that the flow of the liquid film could not be hindered by the adhered deposits as it happened in the experiment. It should also be noted that the applied 2D liquid film model cannot model the transport of solid deposits by the shear forces of the flow if solid deposits do not adhere to the plate.

The thickness of the liquid film had been continuously increasing until it reached the critical value of $400 \mu \mathrm{m}$, which was equal to the thickness of the first prism layer in the fluid region. Further simulation of the deposit formation was not possible due to the divergence of the solution. The thickness of the first prism layer in the fluid region could not be increased substantially due to the fact that it would have led to the overprediction of the initial temperature field on the plate as shown in Fig. 3. The limit of the simulated liquid film thickness to the thickness of the first prism layer in the fluid region is one of the main disadvantages of the used 2D liquid film model.

Figure $6 \mathrm{a}$ and $\mathrm{b}$ illustrate the comparison of the simulated and the measured temperature fields on the bottom side of the impingement plate after $180 \mathrm{~s}$. The position of the cooling spot and the minimal temperature are well predicted. Figure $6 \mathrm{c}$ shows the time resolved progress of the measured and the simulated average temperature drop within the "constrained plane sections" (CP) 4, 5, 6 and the strongest temperature drop on bottom side of the plate. The simulation results show a very good agreement with the measured data in terms of the minimal temperature and the temperature drop within the initial foot print area of the spray (CP 4 and 5). This allows to assume a correct production of the liquid film by source terms of water and urea as well as the correct modeling of the wall cooling above the critical temperature at the beginning of the experiment. The overestimated wall cooling within the CP 6 is related to the overpredicted spreading of the liquid film.

The formation of the film components is plotted in Fig. 7. The blue and red lines represent UWS and solid deposits, respectively. The following successive physical effects can be distinguished in the diagram: Leidenfrost effect and permanent wall wetting after $18 \mathrm{~s}$ of injection. After approx. $70 \mathrm{~s}$, 
Fig. 4 Heat source and urea mass source applied to the film phase during modeling of the experiment 1. (a) Start of injection; (b) 60th second after start of injection

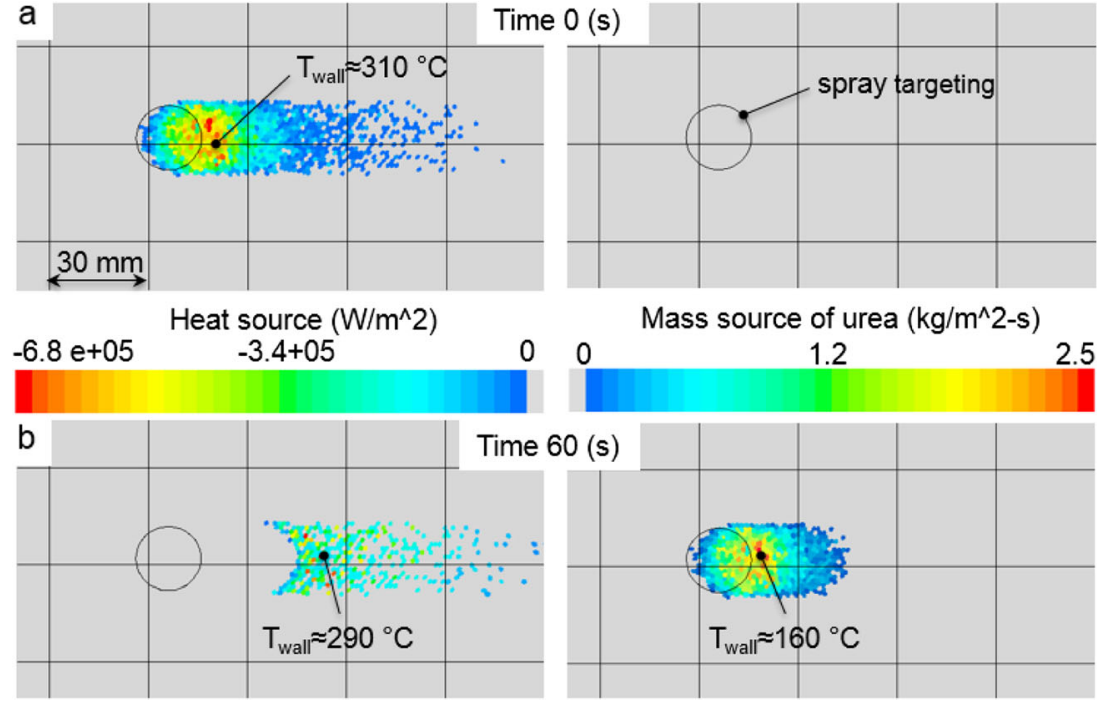

liquid film started a fast propagation from the initial foot print area of the spray. Due to a faster covering of new hot areas by the liquid film, the deposit formation was accelerated considerably. Figure 7 shows also the changes of the solid deposit and UWS mass during the five injection cycles. The "zigzag" structure of the line, which represents solid deposits, can be explained by periodic appearance of crystallized urea. Urea crystallizes for a short time if the film temperature drops below $133{ }^{\circ} \mathrm{C}$ due to a rapid water evaporation. The "zigzag" structure of UWS is a result of the periodic supply of the fresh urea and water at the beginning of each injection cycle and they fast evaporation.

During the simulation time of $180 \mathrm{~s}, 98 \mathrm{mg}$ of solid deposits were accumulated in the film. The main component of the simulated deposits is biuret. In contrast to that, TGA analysis of the deposits generated in this experiment revealed cyanuric acid as the main component. Figure 8 shows TGA measurements of the generated deposits in comparison with the decomposition of pure cyanuric acid. As cyanuric acid decomposition is initiated at temperature of $260^{\circ} \mathrm{C}$ [11], similarity of the decomposition behavior indicates a large portion of cyanuric acid in the deposit sampled from the experiment 1 . A second decomposition stage is visible around $360^{\circ} \mathrm{C}$ for the deposit from the experiment 1 , indicating the presence of small amounts of ammelide. Results show a residual mass of the sample of about $10 \mathrm{wt} .-\%$, which is not decomposed up to temperature of $600{ }^{\circ} \mathrm{C}$. This suggests the presence of temperature resistant species that are not included in current mechanisms of urea decomposition [8]. The deviations of the remaining mass in the TGA analysis of deposit from the experiment 1 and 2 may relate to the slightly different initial composition of investigated samples.

Different compositions of simulated and real solid deposits can be explained by the limited simulation time. In
Fig. 5 Film and deposit formation on the impingement plate in the experiment 1. (a) Simulated film thickness; (b) simulated thickness of solid deposits; (c) experimental result
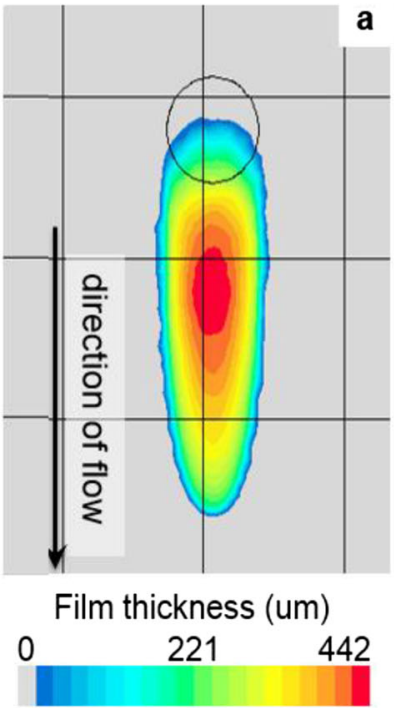

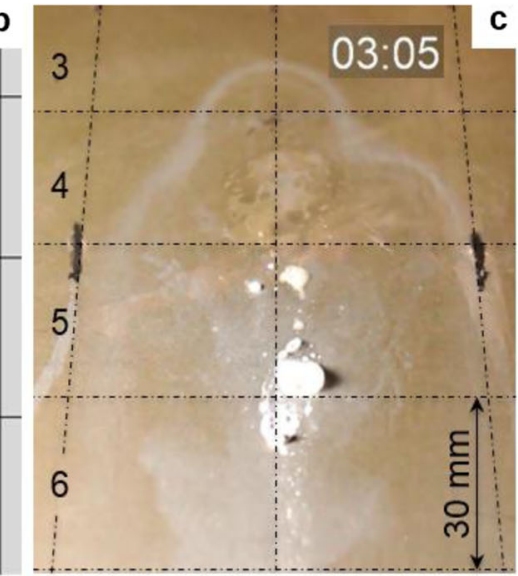

Thickness of deposits(um)

0

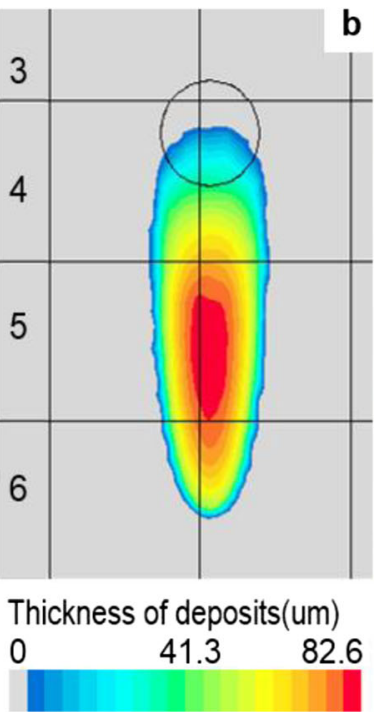

C 
Fig. 6 Simulated (a) and measured (b) temperature drop at the bottom side of the impingement plate for the experiment 1 after $180 \mathrm{~s}$ of the AdBlue injection. (c) Time plot of simulated and measured averaged temperature drop on the bottom side of the impingement plate
Fig. 7 Simulated mass of UWS and solid deposit for the experiment 1

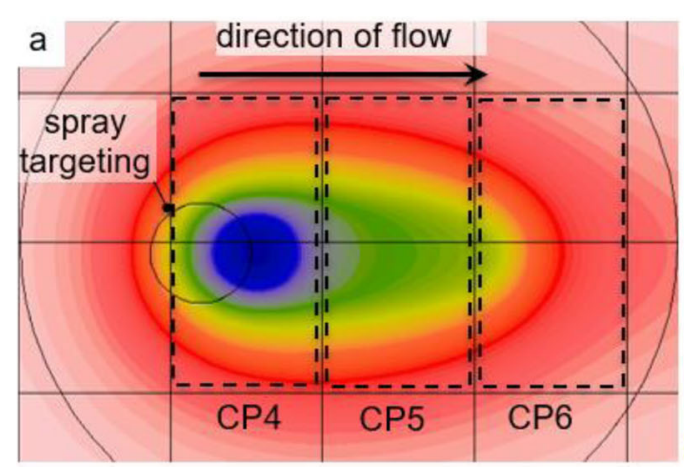

Temperature drop (C)

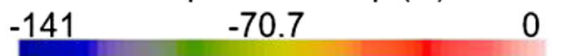

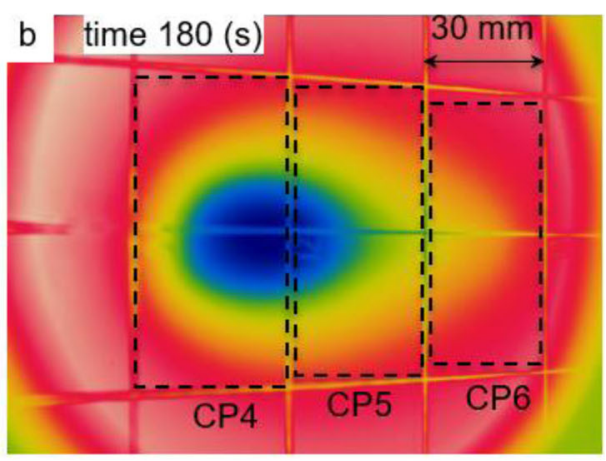

\section{Temperature drop (C)}

$\begin{array}{ll}-141 & -70.7\end{array}$

0
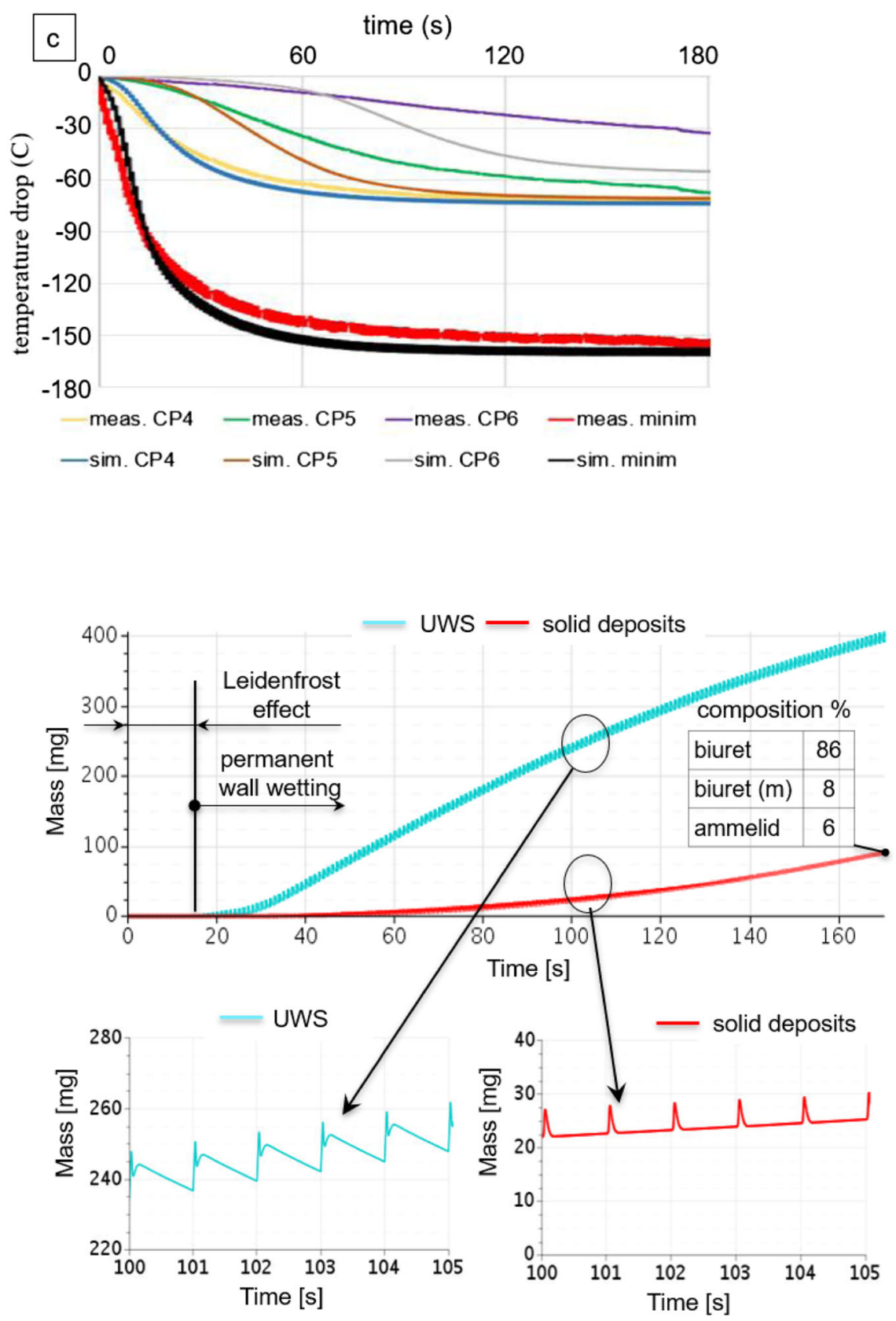


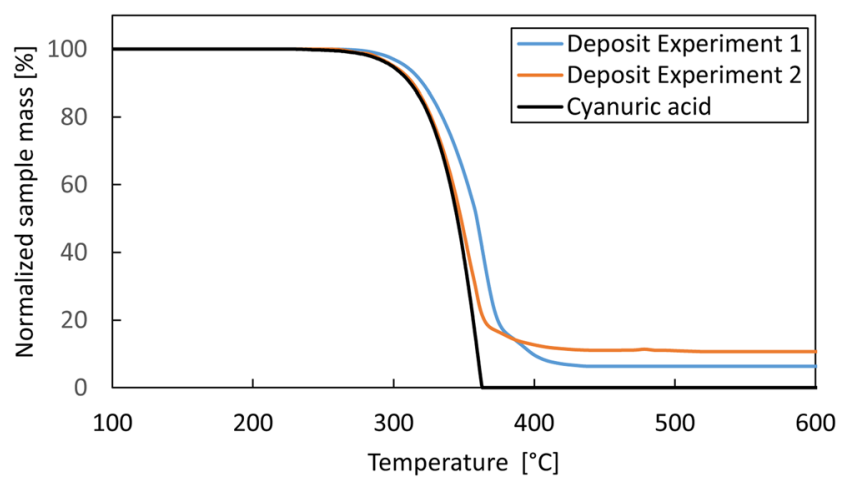

Fig. 8 Measurement results from thermogravimetric analysis of deposits sampled from the experiment 1 and 2 in comparison with pure cyanuric acid decomposition

the experiment, deposits were sampled and analyzed after $20 \mathrm{~min}$, while simulation duration is limited to $180 \mathrm{~s}$. This confines the quantitative comparability of the experimental and numerical results for deposit composition. With increasing simulation time, decomposition of biuret to cyanuric acid is expected as the temperature is above the implemented biuret decomposition temperature of $193{ }^{\circ} \mathrm{C}$. Additionally, further development of the kinetic model may lead to increased model accuracy, which was recently shown by Tischer et al. [46].

In order to examine the accuracy of the developed injection source approach, the first $40 \mathrm{~s}$ of the experiment 2 were modeled both, with the injection source and the Lagrangian approach. Figure 9 a-c show a good agreement between the temperature drops modeled with both approaches. Figure $9 \mathrm{~d}$ illustrates the time resolved progress of the mass of solid species in the liquid film. The simulation with the injection source approach and the time step of $10 \mathrm{~ms}$ showed the same formation of solid deposit as it was predicted by the simulation with the Lagrangian approach and the time step of $0.3 \mathrm{~ms}$. Overall, the accuracy of the developed injection source approach is
Fig. 9 Simulation results obtained with detailed modeling of the Lagrangian phase and the injection source approach for the experiment 2. (a, b) Temperature drop on the bottom side of impingement plate. (c) Time plot of simulated and measured temperature drop. (d) Time plot of the formation of solid deposits
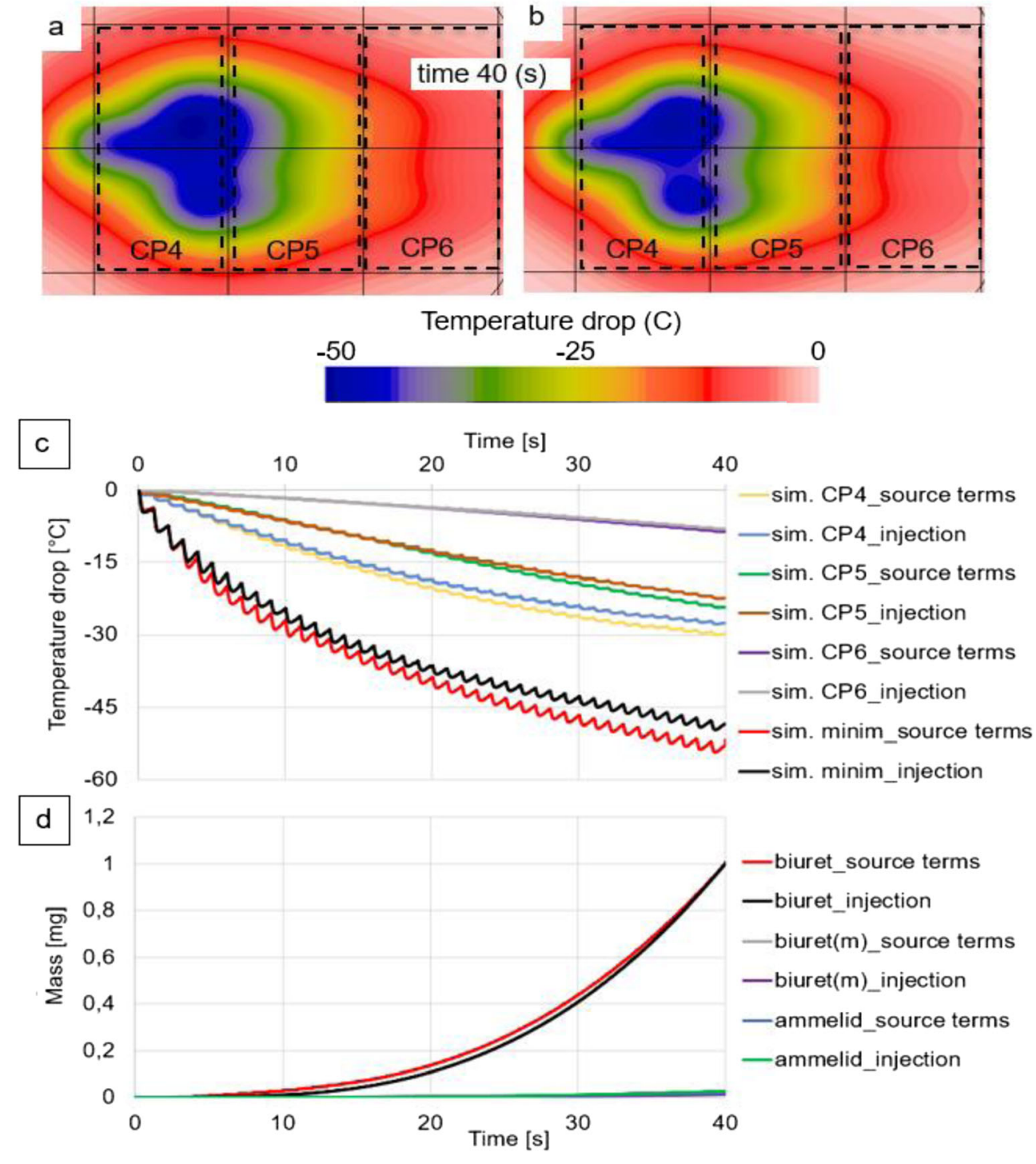
considered as high enough to reproduce the impact of Lagrangian parcels on the gas and liquid film phase.

Figure 10 shows the simulated and experimentally observed liquid film and solid deposit on the impingement plate for OCs of the experiment 2. The liquid film was accumulated during the first part of the experiment, i.e. 300 s. The spreading area of the film and the position of the solid deposits at this time were well predicted. Nevertheless, the width of the simulated liquid film downstream the initial foot print area is larger than the width of the real liquid film. The main reason for that was mentioned above (see the simulation results of the experiment 1). It should be noted that the difference may also be related to a possible inaccuracy in the modeling of the surface tension and viscosity of liquid urea and pseudo liquid film components. To the best of our knowledge, such experimental data for film temperatures above $160^{\circ} \mathrm{C}$ are still missing.

After $300 \mathrm{~s}$, the AdBlue injection was stopped. Hence, the film temperature started to rise and a fast film evaporation was observed. Further propagation of the film was inhibited due to a high viscosity of the solid species in the film. The final position of solid deposit at the time of $20 \mathrm{~min}$ was overpredicted by approx. $40 \mathrm{~mm}$.

Figure $11 \mathrm{a}$ and $\mathrm{b}$ show the comparison of the simulated and measured temperature drop at the end of the first part of the experiment. The temperature drop in the initial foot print area of the spray is in a good agreement with the measured data. Due to a wider front of the simulated liquid film, the cooling area within the CP 6 is overestimated. Figure $11 \mathrm{c}$ shows the time resolved progress of the
Fig. 10 Film and deposit formation on the impingement plate for the experiment 2. (a) Simulated film thickness; (b) simulated thickness of solid deposits; (c) experimental result
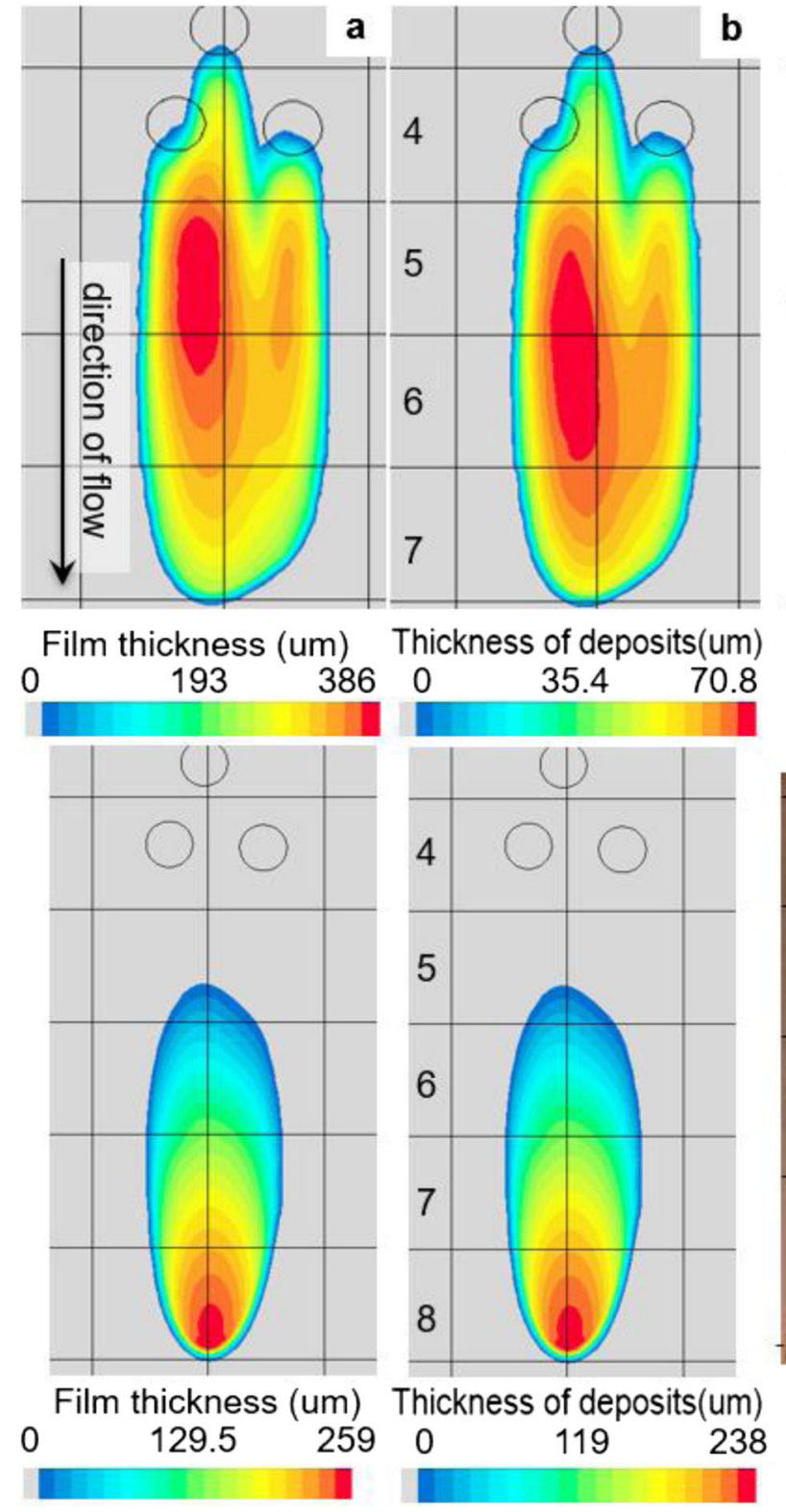
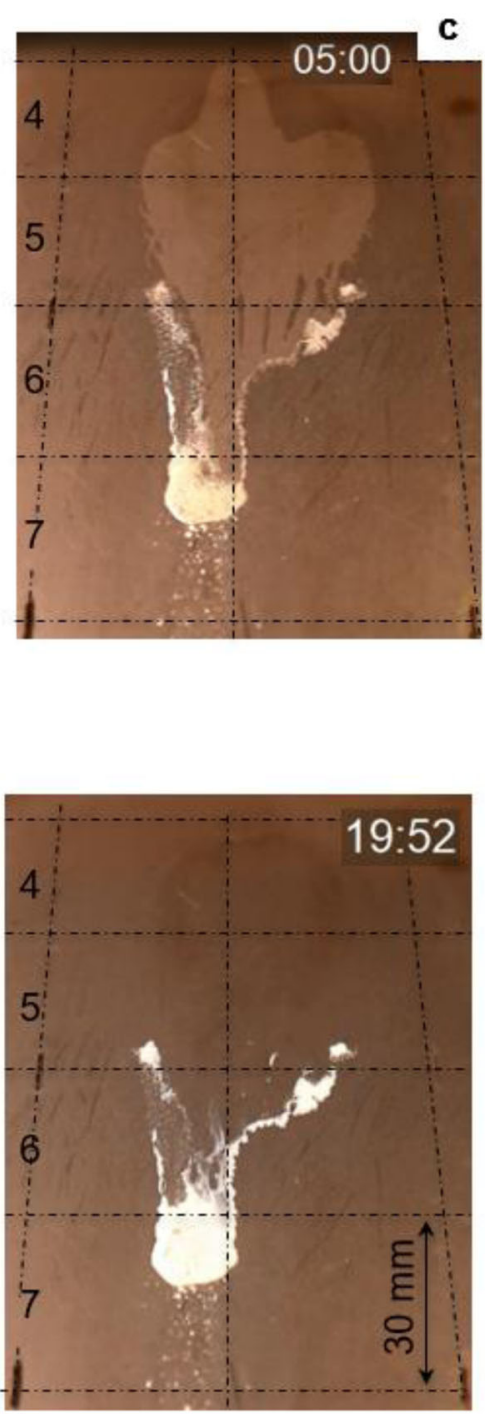
Fig. 11 Simulated (a) and measured (b) temperature drop at the bottom side of the impingement plate. Experiment 2
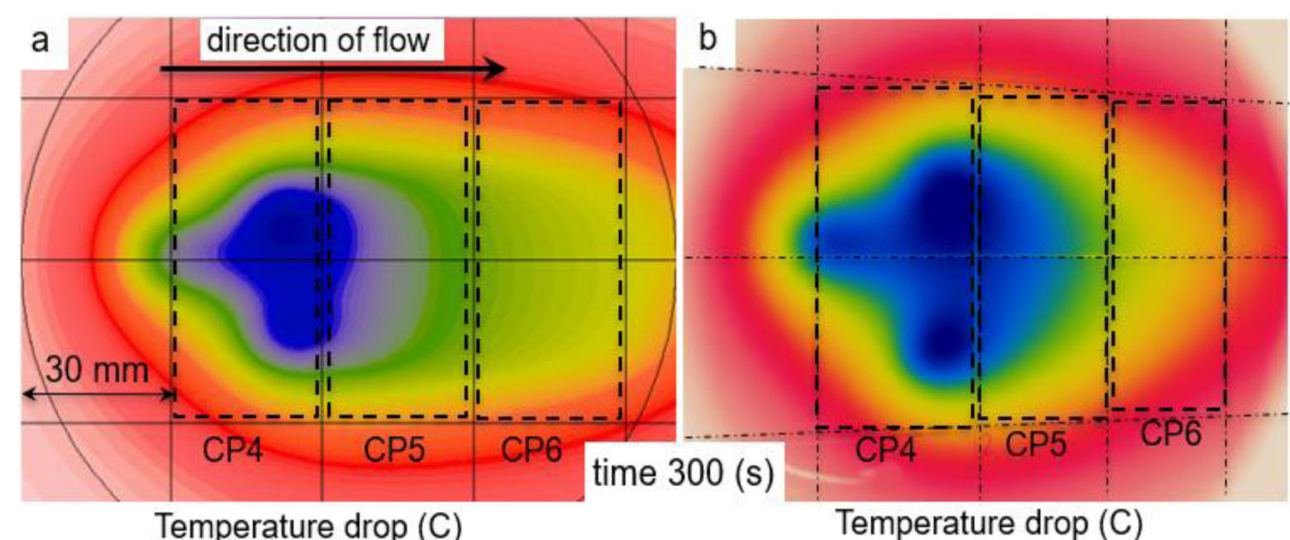

$-69$ $-35.5$ 0 $-69$

Temperature drop (C)

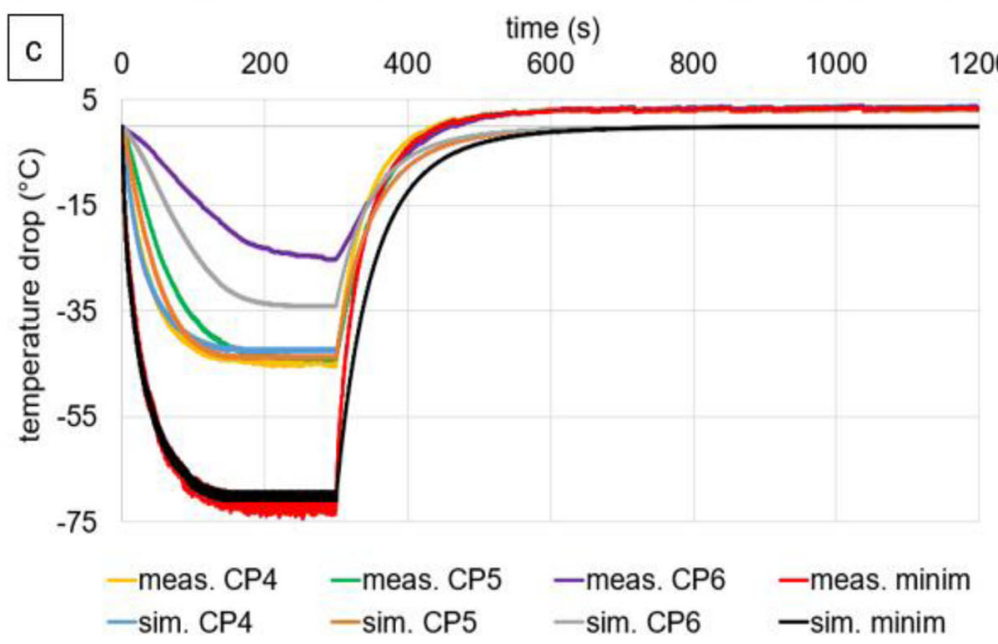

measured and the simulated average temperature drop. Similar to the experiment 1 , the wall cooling in the initial foot print area is well predicted during the whole experiment.
The formation and decomposition of the film components is plotted in Fig. 12. Due to a low initial plate temperature, permanent wall wetting was observed immediately after the start of the AdBlue injection. A fast deposit formation
Fig. 12 Simulated mass of UWS and solid deposits for the experiment 2

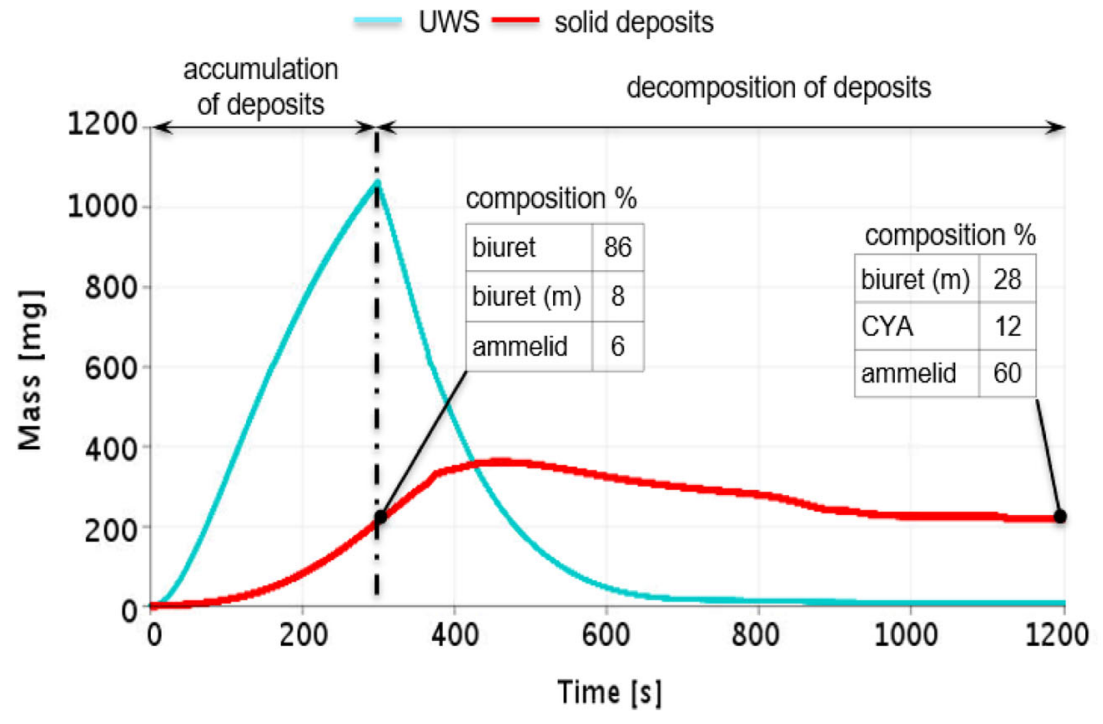


Fig. 13 Relevant biuret reactions implemented in the kinetic model [11]

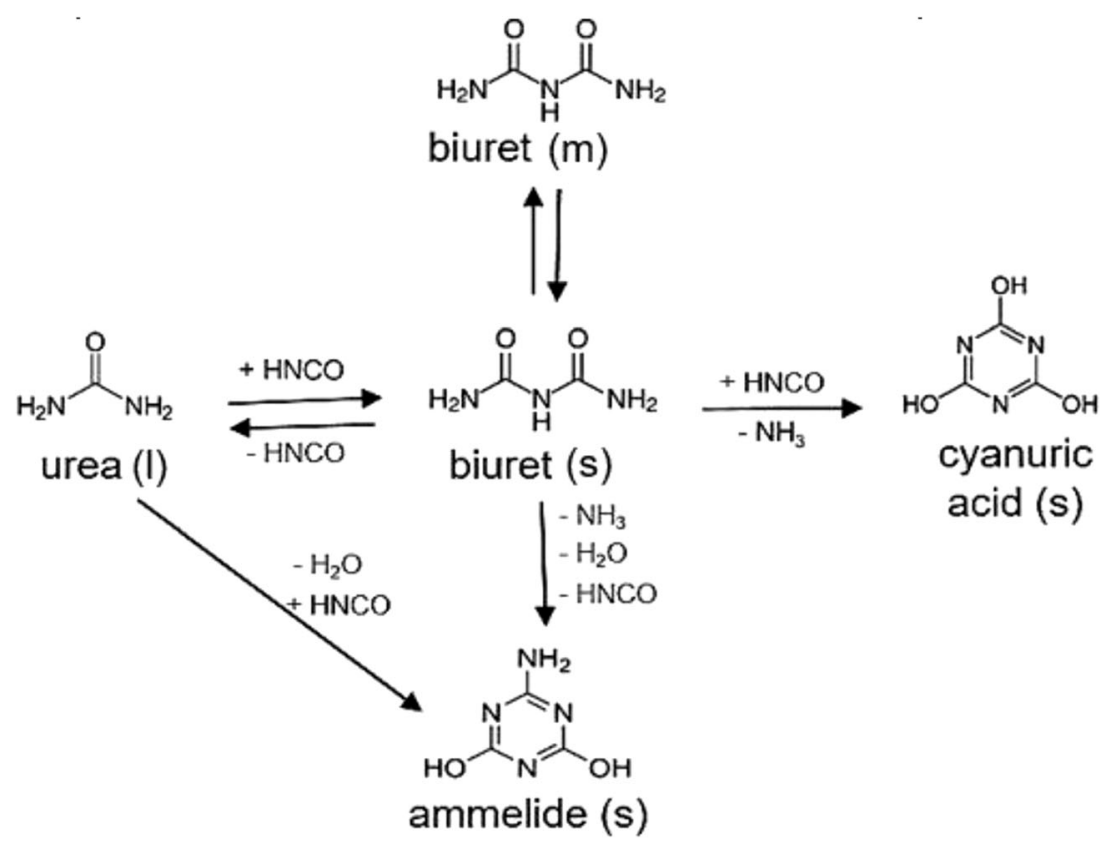

occurred after the liquid film had spread beyond the area of the initial foot print (after approx. $80 \mathrm{~s}$ ). The main component of the simulated deposits at the end of the first part of the experiment was biuret (86\%). After $300 \mathrm{~s}$, the film temperature started to rise, which caused the decomposition of biuret to ammelide (60\%), biuret matrix (28\%) and cyanuric acid (12\%) (Fig. 12). The measured decomposition kinetics of the deposits sampled from the experiment 2 shows a large similarity to deposits from the experiment 1 , as shown in Fig. 8. The solid deposit from the experiment 2 mainly consists on the cyanuric acid.

Deviations in quantitative deposit composition for the experiment and simulation may relate to a low concentration of the isocyanic acid in the simulated liquid film. Isocyanic acid is necessary for the reaction of the biuret to the cyanuric acid as shown Fig. 13. A high saturation pressure of the isocyanic acid leads to a fast evaporation of this species from the liquid film and, hence, the lack of this species for the reaction with biuret. The revision of the thermodynamic properties of this

Table 3 HPLC results for quantitative deposit composition

\begin{tabular}{lll}
\hline Experiment & 1 & 2 \\
\hline Urea & 0.0 & 4.6 \\
Biuret & 0.0 & 0.0 \\
Triuret & 0.0 & 0.0 \\
Cyanuric acid & 88.1 & 81.6 \\
Ammelide & 7.1 & 12.2 \\
Ammeline & 0.0 & 1.4 \\
Melamine & 0.0 & 0.0 \\
Recovery & 95.2 & 99.8 \\
\hline
\end{tabular}

species may improve the simulation results in term of the deposit composition.

HPLC results of deposit samples generated at identical temperature conditions support the TGA results, revealing cyanuric acid as the main component. The measured compositions shown in Table 3 further confirm the increased amount of ammelide for the deposit sample from the experiment 2 .

\section{Conclusion}

For the experimental investigation of deposit formation and decomposition, an engine test bench was developed. The relevant physical and chemical processes were studied with advanced measuring techniques under realistic OCs. Liquid film formation and subsequent growth of solid deposit were observed with video imaging and IR-thermography. The obtained deposits were analyzed using TGA and HPLC measurements.

For modeling of deposit formation, a simulation model including turbulent flow, heat transfer, UWS injection, liquid film and deposit formation was set up. Apart from that, a new speed-up method called "injection source approach" was implemented in order to substantially speed up the CFD simulations. This method allowed to pre-tabulate the sources of mass, momentum and energy for an injection event at given thermodynamic boundary conditions and substitute Lagrangian parcels in the subsequent long-time simulations. It helped to cover the time of several minutes, which is typical for the formation of solid deposits. A simulated physical time of approx. $45 \mathrm{~s}$ /day was achieved by using a computer core 
(Intel Xeon CPU E5-2660 v2 (2.20 GHz)) per 35,000 cells. To the best of our knowledge, that is well beyond typical capabilities of the modeling of deposit formation.

The obtained simulation results are in a good agreement with the measured data in terms of the wall cooling and the film formation within the initial foot print area of the spray, the film propagation and the position of the solid deposit. Nevertheless, some essential disadvantages of the used 2D liquid film model were discovered. The simulated liquid film thickness was limited to the thickness of the first prism layer in the fluid region. Furthermore, the simulated spreading area of the film in the experiment 2 was significantly overestimated. More realistic modeling of thick films can be achieved by simulations with more complicated 3D models of liquid film such as "Volume of fluid (VOF)" or a hybrid of the 2D film model and VOF [33]. Due to a high computation effort for these models, a significant rise of the required simulation time is expected.

Despite the deviations in quantitative composition of the deposits in the experiment and simulation, results show the predictive capability of the presented modeling approach. For a better prediction of the quantitative composition, the implementation of the recently published kinetic model by Tischer et al. [46] is recommended. Moreover, the revision of the thermodynamic properties of isocyanic acid may also improve the simulation results.

Acknowledgments We would like to thank Sabrina Schwarz from the Institute for Chemical Technology and Polymer Chemistry (ITCP), KIT, for her assistance with the HPLC measurements and Dr. Steffen Tischer (ITCP, KIT) for fruitful discussions on the DETCHEMMPTR code. The presented computational results have been achieved using the Vienna Scientific Cluster (VSC).

Funding Information Open access funding provided by TU Wien (TUW). This paper is the scientific result of a research project undertaken by the FVV (The Research Association for Combustion Engines eV). Special thanks are due to the AiF (German Federation of Industrial Research Associations eV) and FFG (Austria Research Promotion Agency) for funding of the project within the framework of the collective research networking (CORNET) programme.

The research was carried out in the framework of the industrial collective programme (IGF/CORNET no. $177 \mathrm{EN})$. It was supported by the Federal Ministry for Economic Affairs and Energy (BMWi) through the AiF (German Federation of Industrial Research Associations eV) based on a decision taken by the German Bundestag. The work of TU Wien was funded by the Federal Ministry of Transport, Innovation and Technology (BMVIT) through the Austria Research Promotion Agency (FFG, grant number 855718). Received funding is greatly acknowledged.

\section{Compliance with Ethical Standards}

The authors declare that they have no competing interests.

Open Access This article is licensed under a Creative Commons Attribution 4.0 International License, which permits use, sharing, adaptation, distribution and reproduction in any medium or format, as long as you give appropriate credit to the original author(s) and the source, provide a link to the Creative Commons licence, and indicate if changes were made. The images or other third party material in this article are included in the article's Creative Commons licence, unless indicated otherwise in a credit line to the material. If material is not included in the article's Creative Commons licence and your intended use is not permitted by statutory regulation or exceeds the permitted use, you will need to obtain permission directly from the copyright holder. To view a copy of this licence, visit http://creativecommons.org/licenses/by/4.0/.

\section{References}

1. Birkhold, F., Meingast, U., Wassermann, P., Deutschmann, O.: Analysis of the Injection of Urea-Water Solution for Automotive SCR DeNOx-Systems: Modeling of Two-Phase Flow and Spray/ Wall-Interaction, SAE Technical Paper 2006-01-0643 (2006)

2. Abu-Ramadan, E., Saha, K., Li, X.: Numerical modeling of the impingement process of urea-water solution spray on the heated walls of SCR systems. SAE Technical Paper. (2012)

3. Grout, S., Blaisot, J.-B., Pajot, K., Osbat, G.: Experimental investigation on the injection of an urea-water solution in hot air stream for the SCR application: evaporation and spray/wall interaction. Fuel. 106, 166-177 (2013)

4. Smith, H., Lauer, T., Mayer, M., Pierson, S.: Optical and numerical investigations on the mechanisms of deposit formation in SCR systems. SAE Int. J. Fuels Lubricants. 7, 525-542 (2014)

5. Brack, W., Heine, B., Birkhold, F., Kruse, M., Deutschmann, O.: Formation of urea-based deposits in an exhaust system: numerical predictions and experimental observations on a hot gas test bench. Emission Control Sci. Technol. 2, 115-123 (2016)

6. Börnhorst, M., Deutschmann, O.: Single droplet impingement of urea-water solution on a heated substrate. Int. J. Heat Fluid Flow. 69, 55-61 (2018)

7. Bai, S.Z., Lang, S.G., Yuan, K.P., Liu, Y., Li, G.X.: Experimental study of urea depositions in urea-SCR system. Adv. Mater. Res. 937, 74-79 (2014)

8. Börnhorst, M., Langheck, S., Weickenmeier, H., Dem, C., Suntz, R., Deutschmann, O.: Characterization of solid deposits from ureawater solution injected into a hot gas test rig. Chem. Eng. J. (2018)

9. Schaber, P.M., Colson, J., Higgins, S., Thielen, D., Anspach, B., Brauer, J.: Thermal decomposition (pyrolysis) of urea in an open reaction vessel. Thermochim. Acta. 424, 131-142 (2004)

10. Bernhard, A.M., Peitz, D., Elsener, M., Wokaun, A., Kröcher, O.: Hydrolysis and thermolysis of urea and its decomposition byproducts biuret, cyanuric acid and melamine over anatase $\mathrm{TiO}$. Appl. Catal. B Environ. 115-116, 129-137 (2012)

11. Brack, W., Heine, B., Birkhold, F., Kruse, M., Schoch, G., Tischer, S., Deutschmann, O.: Kinetic modeling of urea decomposition based on systematic thermogravimetric analyses of urea and its most important by-products. Chem. Eng. Sci. 106, 1-8 (2014)

12. Strots, V.O., Santhanam, S., Adelman, B.J., Griffin, G.A., Derybowski, E.M.: Deposit formation in urea-SCR systems. SAE Int. J. Fuels Lubricants. 2, 283-289 (2009)

13. Eakle, S., Kroll, S., Yau, A., Gomez, J., Henry, C.: Investigation of urea derived deposits composition in SCR systems and their potential effect on overall PM emissions. SAE Technical Paper. (2016)

14. Varna, A., Spiteri, A.C., Wright, Y.M., Dimopoulos Eggenschwiler, P., Boulouchos, K.: Experimental and numerical assessment of impingement and mixing of urea-water sprays for nitric oxide reduction in diesel exhaust. Appl. Energy. 157, 824-837 (2015)

15. Nayak, N.S.: The evaporation and Spray Wall interaction behavior of urea water solution (UWS) in selective catalytic reduction (SCR) Systems of Modern Automobiles. SAE Technical Paper. (2013) 
16. Fischer, S., Bitto, R., Lauer, T., Krenn, C., Tauer, J., Pessl, G.: Impact of the turbulence model and numerical approach on the prediction of the Ammonia homogenization in an automotive SCR system. SAE Int. J. Engines. 5, 1443-1458 (2012)

17. Budziankou, U., Lauer, T., Yu, X., Schmidt, B.M., Cho, N.: Modeling approach for a Wiremesh substrate in CFD simulation. SAE Int. J. Fuels Lubricants. (2017)

18. Michelin, J., Nappez, P., Guilbaud, F., Hinterberger, C., Ottaviani, E., Gauthier, C., Maire, P., Couturier, T.: Advanced close coupled SCR compact mixer architecture. SAE Technical Paper. (2015)

19. Birkhold, F., Meingast, U., Wassermann, P., Deutschmann, O.: Modeling and simulation of the injection of urea-water-solution for automotive SCR DeNOx-systems. Appl. Catal. B Environ. 70, 119-127 (2007)

20. Kontin, S., Höfler, A., Koch R., Bauer H -J.: Heat and mass transfer accompanied by crystallisation of single particles containing ureawater-solution, ILASS - Europe, 23rd Annual Conference on Liquid Atomization and Spray Systems (2010)

21. Stein, M., Bykov, V., Maas, U.: The effect of evaporation models on urea decomposition from urea-water-solution droplets in SCR conditions. Emission Control Sci. Technol. 3, 263-274 (2017)

22. Nishad, K., Sadiki, A., Janicka, J.: Numerical investigation of AdBlue droplet evaporation and thermal decomposition in the context of NOx-SCR using a multi-component evaporation model. Energies. 11, 222 (2018)

23. Smith, H., Zöchbauer, M., Lauer, T.: Advanced spray impingement modelling for an improved prediction accuracy of the ammonia homogenisation in SCR systems. SAE Int. J. Fuels Lubricants. (2015)

24. Eichelbaum, M., Siemer, A.B., Farrauto, R.J., Castaldi, M.J.: The impact of urea on the performance of metal-exchanged zeolites for the selective catalytic reduction of NOx-part II. Catalytic, FTIR, and NMR studies. Appl Catal B Environ. 97, 98-107 (2010)

25. Wurzenberger, J.C., Wanker, R.: Multi-Scale SCR Modeling, 1D Kinetic Analysis and 3D System Simulation. SAE Technical Paper. (2005)

26. Sadashiva Prabhu, S., Nayak, N.S., Kapilan, N., Hindasageri, V.: An experimental and numerical study on effects of exhaust gas temperature and flow rate on deposit formation in urea-selective catalytic reduction (SCR) system of modern automobiles. Appl. Therm. Eng. 111, 1211-1231 (2017)

27. Schellander, D., Pachler, K., Schmalhorst, C., Nahtigal, A.: Predictive Numerical Models and Methods for Selective Catalytic Reactor Applications in Diesel Powered Vehicles, COMODIA 9 (2017)

28. Habchi, C., Nicolle, A., Gillet, N.: Numerical Study of Deposits Formation in SCR Systems Using Urea-Water Solution Injection. J Mater Sci Nanotechnol. 6, (2018)

29. Stiesch, G.: Modeling Engine Spray and Combustion Processes. Springer, Berlin Heidelberg (2003)

30. Fischer, S.: Simulation of the urea-water-solution preparation and ammonia homogenization with a validated CFD-model for the optimization of automotive SCR-systems, $\mathrm{PhD}$ thesis, Vienna, Austria
31. Bhattacharjee, S., Haworth, D.C., Moores, R.: CFD modeling of processes upstream of the catalyst for urea SCR NOx reduction systems in heavy-duty diesel applications. SAE Technical Paper. (2011). https://doi.org/10.4271/2011-01-1322

32. Smith, H.: Modelling deposit formation in automotive SCR systems, $\mathrm{PhD}$ thesis, Vienna, Austria

33. Siemens, Siemens Product Lifecycle Management Software Inc., The Steve Portal: Selective Catalytic Reduction Best Practices by Steven Dowding, 2018, www.thesteveportal.plm.automation. siemens.com

34. Kuhnke, D.: Spray wall interaction modelling by dimensionless data analysis, $\mathrm{PhD}$ thesis, Aachen

35. Birkhold, F.: Selektive katalytische Reduktion von Stickoxiden in Kraftfahrzeugen: Untersuchung der Einspritzung von Harnstoffwasserlösung, $\mathrm{PhD}$ thesis, Karlsruhe, Germany

36. Bai, C.: Modelling of spray impingement processes, $\mathrm{PhD}$ Thesis, London, UK

37. Koebel, M., Elsener, M.: Determination of urea and its thermal decomposition products by high-performance liquid chromatography. J. Chromatogr. A. 689, 164-169 (1995)

38. Bernhard, A.M., Czekaj, I., Elsener, M., Wokaun, A., Kröcher, O.: Evaporation of urea at atmospheric pressure. J. Phys. Chem. A. 115(12), 2581-2589 (2011)

39. Schiller, L., and Naumann: Über die grundlegenden Berechnungen bei der Schwerkraftaufbereitung, VDI Zeitschrift (1933)

40. Wruck N.: Transientes Sieden von Tropfen beim Wandaufprall, $\mathrm{PhD}$ thesis, Aachen, Germany

41. N. Garcia Rosa, P. Villedieu, J. Dewitte, G. Lavergne, A New Droplet-Wall Interaction Model, 10th International Conference on Liquid Atomization and Spray Systems, ICLASS (2006)

42. O. Deutschmann, S. Tischer, S. Kleditzsch, V. Janardhanan, C. Correa, D. Chatterjee, N. Mladenov, H.D. Minh, H. Karadeniz, M. Hettel, V. Menon, A. Banerjee, DETCHEM Software Package, 2018, www.detchem.com

43. Mundo, C., Sommerfeld, M., Tropea, C.: Droplet-wall collisions: experimental studies of the deformation and breakup process. Int. J. Multiphase Flow. 21, 151-173 (1995)

44. Quissec, M., Lauer, T., García-Afonso, O., Fowles, S.: Identification of film breakup for a liquid urea-water-solution and application to CFD. SAE Technical Paper. (2019). https://doi.org/ 10.4271/2019-01-0983

45. Deuflhard, P., Hairer, E., Zugck, J.: One-step and extrapolation methods for differential-algebraic systems. Numer. Math. 51, 501-516 (1987)

46. Tischer, S., Börnhorst, M., Amsler, J., Schoch, G., Deutschmann, O.: Thermodynamics and reaction mechanism of urea decomposition. Phys. Chem. Chem. Phys. (2019)

Publisher's Note Springer Nature remains neutral with regard to jurisdictional claims in published maps and institutional affiliations. 